To appear in Vehicle System Dynamics

Vol. 00, No. 00, January 2019, 1-21

\title{
Using an Inerter-Based Suspension to Improve Both Passenger Comfort and Track Wear in Railway Vehicles
}

\author{
T.D. Lewis ${ }^{\mathrm{a}}$, J.Z. Jiang ${ }^{a *}$, S.A. Neild ${ }^{\mathrm{a}}$, C. Gong ${ }^{\mathrm{b}}$ and S.D. Iwnicki ${ }^{\mathrm{c}}$ \\ ${ }^{a}$ Queen's Building, University of Bristol, University Walk, Bristol, BS8 1TR, UK ${ }^{b}$ Rail and \\ Transit Infrastructure department, SNC Lavalin, 9A Devonshire Square, London, EC2M 4YN, \\ UK ${ }^{c}$ Institute of Railway Research, University of Huddersfield, Queensgate, Huddersfield, \\ HD1 3DH, UK [Word Count: 5500 (approx)]
}

(Received 00 Month 20XX; accepted 00 Month 20XX)

\begin{abstract}
There is an increasing desire in the railway industry to improve the longevity of wheels and rails without reducing performance in other ways (e.g. worsening passenger comfort). One way of reducing track and wheel wear is to reduce the primary yaw stiffness, significantly diminishing the costs associated with maintenance and emergency repairs, resulting however in reduced passenger comfort and high-speed stability. This paper, using a two-axle railway vehicle case study, demonstrates the potential of using passive, inerter-based suspensions to concurrently improve ride comfort and reduce track wear. The industrial parameter $T_{\gamma}$ is used to quantify the frictional energy lost at the contact patch under curving conditions, and the lateral RMS carbody acceleration is used to quantify passenger comfort under straight running conditions, with lateral track disturbances taken from real track data. Optimisation results conclude that, with the default yaw stiffness value, compared with the default springdamper configuration in the primary lateral suspension, employing beneficial inerter-based configurations can improve passenger comfort by up to $43 \%$. If the yaw stiffness is reduced such that the track wear is improved, similar improvements in passenger comfort can still be achieved with lateral inerter-based suspensions; for example, an improvement of $33 \%$ can still be achieved with a $50 \%$ reduction in yaw stiffness. Furthermore, when an inerter-based lateral suspension is used together with a Hall-Bush longitudinal suspension, the passenger comfort rises to $40 \%$, which relates to a $25 \%$ improvement when compared with a non-inerter lateral plus Hall-Bush longitudinal setup.
\end{abstract}

Keywords: Inerter, suspension, vibration, railway vehicle.

\section{Introduction}

The trade-off between reducing railway vehicles' lateral carbody acceleration whilst on a straight track and reducing the magnitude of the wheel-rail creep forces under curving conditions has long been problematic. When a railway vehicle travels around a curve, a decreased static longitudinal stiffness (and therefore the primary yaw stiffness) results in a reduction in the energy lost due to friction at the contact patch, quantified by the commonly used parameter, $T_{\gamma}$ [1]. Reducing $T_{\gamma}$ leads, for moderate values of $T_{\gamma}$, to a reduction in Rolling Contact Fatigue (RCF), which in turn reduces the maintenance costs related to the tracks and wheels, and the overall Track Access Charge (TAC). However, a decrease in primary yaw stiffness can lead to a loss of stability and an increase in

\footnotetext{
*Corresponding author. Email: z.jiang@bristol.ac.uk
} 
the lateral acceleration of the vehicle body during straight running conditions, causing a deterioration in passenger comfort as the wheelset and the carbody move increasingly less independently from one another. A loss of stability is also problematic from a safety perspective, as this would make the vehicle more susceptible to derailment and increase the risk of it being blown over in gales.

Active railway vehicle control methods have been successfully studied, e.g. [2-4], with suitable control laws being established. It should be noted that superior vibration suppression can be achieved with active rather than passive components, however risks such as actuator malfunction, measurement error as well as problems such as low fault tolerances and high power requirements prevent the wide real-life application of this solution. A recently introduced passive vibration suppression technique which successfully combats the trade-off described above is the use of the Hall-Bush structure in the longitudinal suspension [5] (see Figure 1(a)). This device, which includes stiffness and damping, enables the yaw stiffness to be reduced, reducing track wear, whilst maintaining a satisfactory level of passenger comfort. The Hall-Bush, which has already been implemented in some vehicles, could also allow for a lower conicity wheel profile to be used, without excessive flangwear becoming an issue. It is also suggested in [5] that, for certain tight radius curves, the damage caused by Rolling Contact Fatigue (RCF) increases with the use of the Hall-Bush.

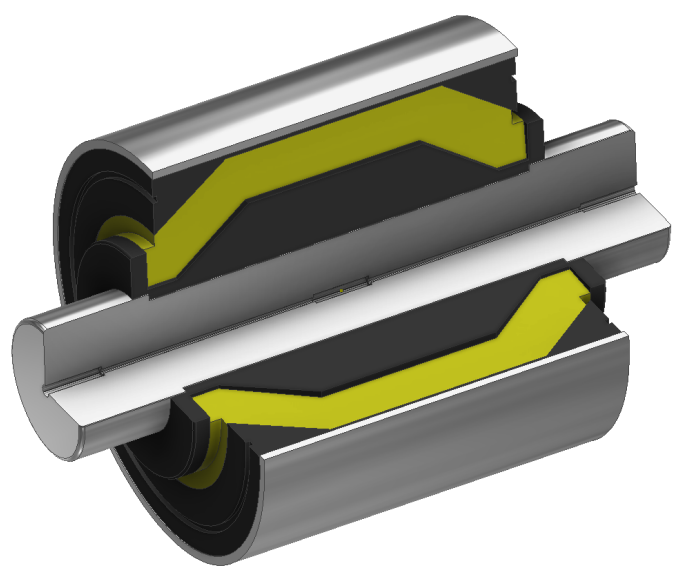

(a) The Hall-Bush

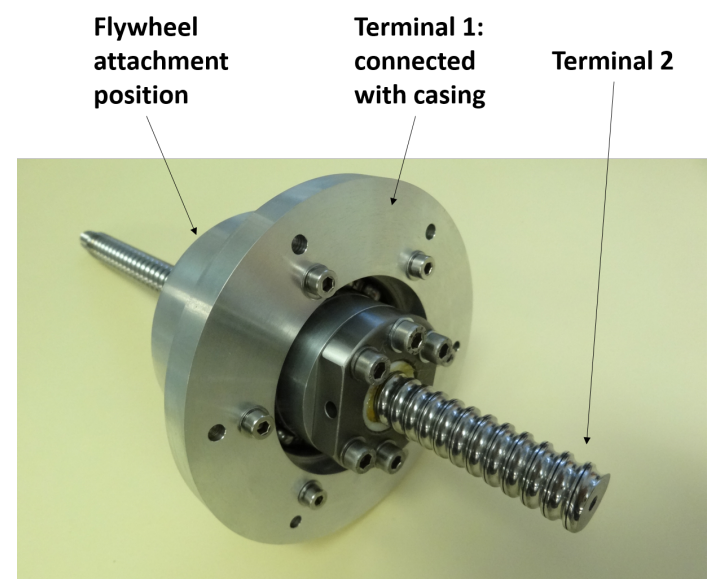

(b) A ball-screw inerter prototype

Figure 1. A CAD drawing of the Hall-Bush device, with the fluid passageways visible in yellow, inspired by the design seen in [5], and A ball-screw inerter, built at the University of Bristol, with its outer casing removed to enable the threaded rod to be seen.

An inerter [6] is a two-terminal mechanical element which exerts a force proportional to the relative acceleration between its terminals. A ball-screw type inerter is shown in Figure 1(b). Inerters are equivalent to capacitors using the force-current analogy, and each possesses a constant value, measured in kg. Mechanical networks combining inerters, springs and dampers can theoretically describe any positive-real transfer function [7]. A preliminary study of the implementation of inerters to a quarter-car model [8], which used a prototype inerter, yielded improvements in ride, tyre normal load and handling of $10 \%$ or greater over conventional spring and damper based passive struts. The use of inerters has recently expanded into buildings [9-11], road vehicles [12-14], aircraft landing gear [15, 16] and optical tables [17]. First proposed in 2002 in the form of a rack and pinion design [6], other inerter designs have been proposed such as the ballscrew inerter used in Formula 1 [18], fluid inerters [19-21] and hydraulic inerters [22]. 
The specific inerter realisation used is highly dependent on the application, space and manufacturing constraints, and the configuration required.

Research into the use of inerters in railway vehicles is ongoing and significant benefits have been identified to date. In [23], a parallel inerter layout in the vertical suspension was identified to be beneficial to a railway vehicle's critical speed, settling time and passenger comfort. In [24] the critical speed of a 16 Degree of Freedom (DoF), two stage suspension railway model built in AutoSim ${ }^{T M}$ was shown to improve when configurations including a parallel inerter are included in the secondary suspension. Using a bogied 7 DoF model, it was concluded in [25] that further ride comfort improvements can be obtained by implementing the inerter into both the secondary and primary lateral suspensions, and [26] provides a detailed summary of the potential benefits inerters can bring to both bogied and two-axle railway vehicles in terms of stability, ride comfort and track wear. Research which uses inerters in conjunction with active mechatronic vibration control strategies [27] demonstrates that combining vertical inerter-based suspensions with a skyhook damping strategy, in a two-axle railway vehicle, results in an active force requirement reduction of $50 \%$ when an improvement in vertical ride quality of $30 \%$ is stipulated. The analysis of a two-axle railway vehicle in [28] investigates only curving performance, using the yaw stiffness as the cost function for the lateral suspension optimisations, whilst ensuring the least damping ratio and ride quality remain at least as good as for the default layout. It concludes that it is possible to allow the yaw stiffness to be reduced, hence reduce the contact patch forces, with inerter-based lateral suspension configurations keeping the ride quality as good as the default value. Significant benefits that inerters can provide to the lateral and vertical ride quality when used in the lateral and vertical suspension respectively are identified in [29].

This work focuses on demonstrating the performance benefits of concurrently improving track wear and passenger comfort with inerter-based suspensions. Furthermore, differing from previous studies, track and wheel wear is assessed by the commonly used industrial parameter $T_{\gamma}$ in this paper. Real lateral track displacement data is used when assessing the vehicle's straight running performance with lateral track disturbances to better simulate real-life track conditions than previous studies. Analysis where both inerter-based lateral suspensions and a Hall-Bush longitudinal suspension is also performed.

The structure of this paper is as follows: Section 2 provides an overview of the theoretical two-axle railway vehicle model and its corresponding transfer function method of simulation; Section 3 explains the passenger comfort performance assessment under straight track conditions used in this study, and introduces $T_{\gamma}$ as a measure of the track and wheel wear under curving conditions; in Section 4 trade-off analysis of minimised lateral RMS carbody acceleration vs $T_{\gamma}$ are shown, and the benefits of using inerterbased configurations are demonstrated in detail; finally, overall conclusions are drawn in Section 5 .

\section{Model Description}

A six DoF railway vehicle model is shown in Figure 2. It is similar to the model used previously in $[28,29]$, within which lateral (to the direction of travel) and yaw motion is considered. The vehicle body (carbody) is connected to the two solid axle wheelsets via suspension layouts $L_{y i}(s)$ in the lateral direction and $L_{x j}(s)$ in the longitudinal (or travel) direction, which are subject to change in this paper. Subscripts $x$ and $y$ here denote the lateral and longitudinal suspension respectively, and subscripts $i$ and $j$ denote 
respectively the specific lateral and longitudinal suspension layouts (see Figure 3). The six states of the system,

$$
x=\left[y_{w 1}, \theta_{w 1}, y_{w 2}, \theta_{w 2}, y_{v}, \theta_{v}\right]^{T},
$$

are defined in Figure 2, with their Equations of Motion (EoMs) being:

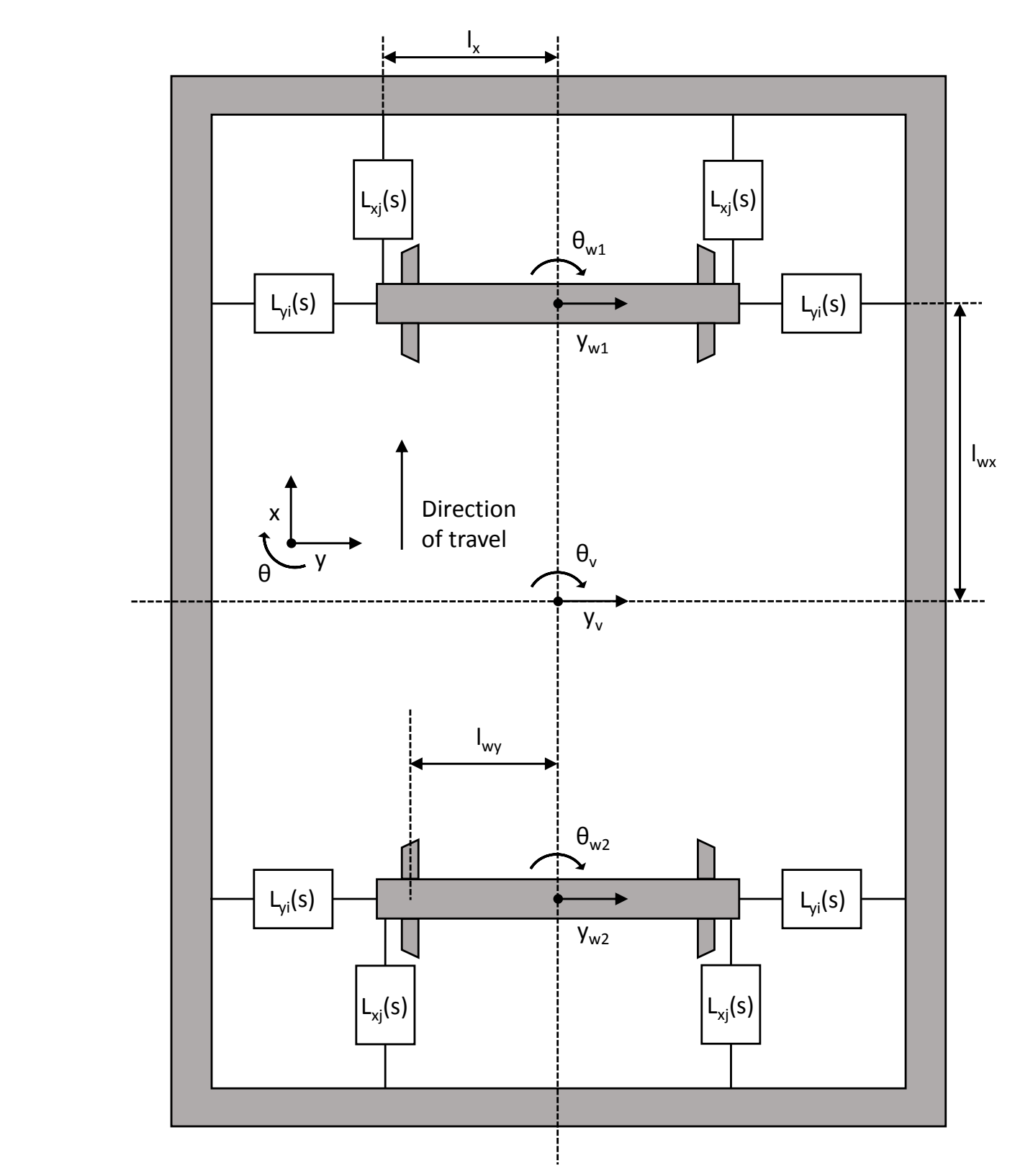

Figure 2. The two-axle, six DoF railway vehicle model with the four lateral $\left(L_{x i}\right)$ and longitudinal $\left(L_{x j}\right)$ suspension positions shown.

are defned in Figue 2, with their Eqtations of Motion (EoMs) being: 


$$
\begin{array}{r}
m_{w} s^{2} \hat{y}_{w 1}=2 s L_{y i}(s)\left(\hat{y}_{v}-\hat{y}_{w 1}\right)-\frac{2 f_{22}}{V} s \hat{y}_{w 1}+2 f_{22} \hat{\theta}_{w 1}+2 s L_{y i}(s) l_{w x} \hat{\theta}_{v}+\frac{2 \varepsilon\left(N-f_{23}\right)}{l_{w y} r_{0}} \hat{y}_{w 1} \\
+m_{w}\left(\frac{V^{2}}{R_{1}}-g \theta_{c 1}\right)
\end{array}
$$

$$
\begin{aligned}
I_{w} s^{2} \hat{\theta}_{w 1}=\frac{2 f_{11} l_{w y}^{2}}{V} s \hat{\theta}_{w 1}-\frac{2 f_{11} \lambda l_{w y}}{r_{0}} \hat{y}_{w 1}+2 s L_{x j}(s) l_{x}^{2}\left(\hat{\theta}_{v}-\hat{\theta}_{w 1}\right) & \\
& -\frac{2 f_{11} \lambda l_{w y}}{r_{0}} \hat{y}_{t 1}+\frac{2 f_{11} L_{w y}^{2}+K_{x} L_{w x}}{R_{1}}
\end{aligned}
$$

$$
\begin{array}{r}
m_{w} s^{2} \hat{y}_{w 2}=2 s L_{y i}(s)\left(\hat{y}_{v}-\hat{y}_{w 2}\right)-\frac{2 f_{22}}{V} s \hat{y}_{w 2}+2 f_{22} \hat{\theta}_{w 2}+2 L_{y i}(s) l_{w x} \hat{\theta}_{v}+\frac{2 \varepsilon\left(N-f_{23}\right)}{l_{w y} r_{0}} \hat{y}_{w 2} \\
+m_{w}\left(\frac{V^{2}}{R_{2}}-g \theta_{c 2}\right)
\end{array}
$$

$$
\begin{aligned}
I_{w} s^{2} \hat{\theta}_{w 2}=\frac{2 f_{11} l_{w y}^{2}}{V} s \hat{\theta}_{w 2}-\frac{2 f_{11} \lambda l_{w y}}{r_{0}} \hat{y}_{w 2}+2 s L_{x j}(s) l_{x}^{2}\left(\hat{\theta}_{v}-\hat{\theta}_{w 2}\right) & \\
& -\frac{2 f_{11} \lambda l_{w y}}{r_{0}} \hat{y}_{t 2}+\frac{2 f_{11} L_{w y}^{2}-K_{x} L_{w x}}{R_{2}}
\end{aligned}
$$

$$
\begin{aligned}
m_{v} s^{2} \hat{y}_{v}=2 s L_{y i}(s)\left(\hat{y}_{w 1}-\hat{y}_{v}\right)+2 s L_{y i}(s)\left(\hat{y}_{w 1}-\hat{y}_{v}\right)+\frac{m_{v} V}{2}\left(\frac{1}{R_{1}}+\frac{1}{R_{2}}\right) & \\
& -\frac{m_{v} g}{2}\left(\theta_{c 1}+\theta_{c 2}\right)
\end{aligned}
$$

$$
\begin{array}{r}
I_{v} s^{2} \hat{\theta}_{v}=2 s L_{y i}(s) l_{w x}\left(\hat{y}_{w 1}-\hat{y}_{v}\right)+2 s L_{y i}(s) l_{w x}\left(\hat{y}_{v}-\hat{y}_{w 2}\right)+2 s L_{x j}(s) l_{x}^{2}\left(\hat{\theta}_{w 1}-\hat{\theta}_{v}\right) \\
+2 s L_{x j}(s) l_{x}^{2}\left(\hat{\theta}_{w 2}-\hat{\theta}_{v}\right)-4 s L_{y i}(s) l_{w x}^{2} \hat{\theta}_{v}
\end{array}
$$

In these equations, $s$ denotes the Laplace variable and for example $\hat{y}_{w 1}$ represents the Laplace Transform of $y_{w 1}(t)$. All parameters are defined in Table 1, expressions for the creep coefficients $f_{11}, f_{22}$ and $f_{23}$ can be seen in Appendix B, and the contact angle parameter which introduces gravitational stiffness and spin creepage terms into Equations $2-7$ is evaluated as follows [30],

$$
\varepsilon=A_{c}\left(\lambda-\lambda_{0}\right) .
$$

The external forces acting on the model arise from the track's cant angle, $\theta_{c}$, radius of curvature, $R$, and lateral displacement, $y_{t}$, from an average lateral datum which arises from irregularities due to heat distortion, wear, and manufacturing shortcomings. The internal forces come about from the longitudinal and lateral suspension configurations; $L_{x j}(s)$ and $L_{y i}(s)$ respectively; along with gravitational stiffness due to the miss-match between each wheel's conicity and its base cone profile angle, and the creep forces at the wheel-rail contact points. To simplify the analysis, similar to previous studies $[4,24,25$, $28,29]$ it is assumed that all contact patches are circular, the track is infinitely stiff, and nonlinear friction saturation is not included in the analysis. 
Table 1. Table of parameters, along with their symbols and units where applicable. The Kalker coefficients and contact angle constant are taken from [30], and the creep coefficients are calculated in Appendix B

\begin{tabular}{|c|c|c|c|}
\hline Symbol & Parameter & Unit & Value \\
\hline$V$ & Vehicle forward speed & $\mathrm{ms}^{-1}$ & $1-35$ \\
\hline$V_{o p}$ & Vehicle nominal operational velocity & $\mathrm{ms}^{-1}$ & 31 \\
\hline$m_{w}$ & Wheelset mass & $\mathrm{kg}$ & $1.25 \times 10^{3}$ \\
\hline$I_{w}$ & Wheelset yaw inertia & $\mathrm{kgm}^{2}$ & 700 \\
\hline$m_{v}$ & Carbody mass & $\mathrm{kg}$ & $3 \times 10^{4}$ \\
\hline$I_{v}$ & Carbody yaw inertia & $\mathrm{kgm}^{2}$ & $5.58 \times 10^{5}$ \\
\hline$l_{x}$ & Semi-lateral spacing of longitudinal suspension connections & $\mathrm{m}$ & 1 \\
\hline$l_{w x}$ & Half the wheelset spacing & $\mathrm{m}$ & 4.5 \\
\hline$l_{w y}$ & Half the vehicle gauge & $\mathrm{m}$ & 0.7 \\
\hline$\lambda$ & Wheel conicity & - & 0.2 \\
\hline$\lambda_{0}$ & Base cone profile & - & 0.05 \\
\hline$r_{0}$ & Nominal wheel radius & $\mathrm{m}$ & 0.45 \\
\hline$y_{t 1}$ & Lateral track displacement at front wheelset & - & - \\
\hline$y_{t 2}$ & Lateral track displacement at rear wheelset & - & - \\
\hline$R_{1}$ & Radius of curved track at front wheelset & $\mathrm{m}$ & $1 \times 10^{3}$ \\
\hline$R_{2}$ & Radius of curved track at rear wheelset & $\mathrm{m}$ & $1 \times 10^{3}$ \\
\hline$\theta_{c 1}$ & Cant angle of curved track at front wheelset & $\mathrm{rad}$ & $\pi / 30$ \\
\hline$\theta_{c 2}$ & Cant angle of curved track at rear wheelset & $\mathrm{rad}$ & $\pi / 30$ \\
\hline$g$ & Gravitational acceleration & $\mathrm{ms}^{-2}$ & 9.81 \\
\hline$\stackrel{\breve{K}}{K_{y}}$ & Default lateral stiffness per axle box & $\mathrm{Nm}^{-1}$ & $2.555 \times 10^{5}$ \\
\hline$K_{x}$ & Default longitudinal stiffness per axle box & $\mathrm{Nm}^{-1}$ & $1 \times 10^{6}$ \\
\hline$c_{s y}$ & Default lateral damping per axle box & $\mathrm{Nsm}^{-1}$ & $1.51 \times 10^{4}$ \\
\hline$c_{s x}$ & Default longitudinal damping per axle box & $\mathrm{Nsm}^{-1}$ & $4 \times 10^{3}$ \\
\hline$A_{l}$ & Lateral track roughness factor & $\mathrm{m}$ & $1.886 \times 10^{-9}$ \\
\hline$v$ & Poisson's ratio of steel & - & 0.3 \\
\hline$E$ & Young's Modulus of steel & $\mathrm{Pa}$ & $2 \times 10^{11}$ \\
\hline $\bar{N}$ & Nominal normal force at each contact patch & $\mathrm{N}$ & $7.971 \times 10^{4}$ \\
\hline$A_{c}$ & Contact angle constant & - & 50.7 \\
\hline$C_{11}$ & Longitudinal Kalker coefficient & - & 1.65 \\
\hline$C_{22}$ & Lateral Kalker coefficient & - & 1.43 \\
\hline$C_{23}$ & Spin Kalker coefficient & - & 0.579 \\
\hline$f_{11}$ & Longitudinal creep coefficient & $\mathrm{N}$ & $1.291 \times 10^{7}$ \\
\hline$f_{22}$ & Lateral creep coefficient & $\mathrm{N}$ & $1.119 \times 10^{7}$ \\
\hline$f_{23}$ & Spin creep coefficient & $\mathrm{N}$ & $2.835 \times 10^{4}$ \\
\hline
\end{tabular}

The use of $\varepsilon$ increases the accuracy of the model compared with [28] and [29]. In the same studies, the six different $L_{y i}(s)$ layouts were investigated as lateral suspension layouts. These, and the two different $L_{x j}(s)$ layouts, are employed in the analysis in this paper in the lateral and longitudinal suspensions respectively (see Figure 3 ). $K_{y}$ and $K_{x}$ denote constant static stiffnesses, $k_{s y}$ and $k_{s x}$ optimisable spring stiffnesses, $c_{s y}$ and $c_{s x}$ optimisable damping coefficients, and $b_{s y}$ and $b_{s y p}$ optimisable series and parallel inertance values respectively. The default values of $K_{y}, K_{x}, c_{s y}$ and $c_{s x}$ are shown in Table 1, the mechanical admittance functions of lateral seen layouts in Figure 3 are shown in Equations 9 - 14, and the admittance functions of the default and Hall-Bush longitudinal layouts (respectively $L_{x 1}$ and $L_{x 2}$ ) are the same as in Equations 9 and 11, but with appropriate variable substitutions made.

$$
L_{y 1}(s)=\frac{K_{y}}{s}+c_{s y} \quad(9) \quad L_{y 2}(s)=\frac{K_{y}}{s}+c_{s y}+b_{s y p} s
$$




$$
L_{y 3}(s)=\frac{K_{y}}{s}+\left(\frac{s}{k_{s y}}+\frac{1}{c_{s y}}\right)^{-1}
$$

$$
L_{y 4}(s)=\frac{K_{y}}{s}+\left(\frac{s}{k_{s y}}+\frac{1}{c_{s y}}\right)^{-1}+b_{s y p} s
$$

$$
\begin{gathered}
L_{y 5}(s)=\frac{K_{y}}{s}+\left(\frac{s}{k_{s y}}+\frac{1}{c_{s y}}+\frac{1}{b_{s y} s}\right)^{-1} \\
L_{y 6}(s)=\frac{K_{y}}{s}+\left(\frac{s}{k_{s y}}+\frac{1}{c_{s y}}+\frac{1}{b_{s y} s}\right)^{-1}+b_{s y p} s
\end{gathered}
$$

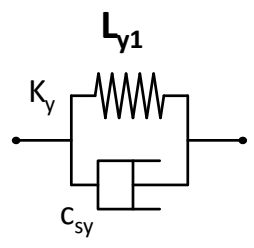

Default
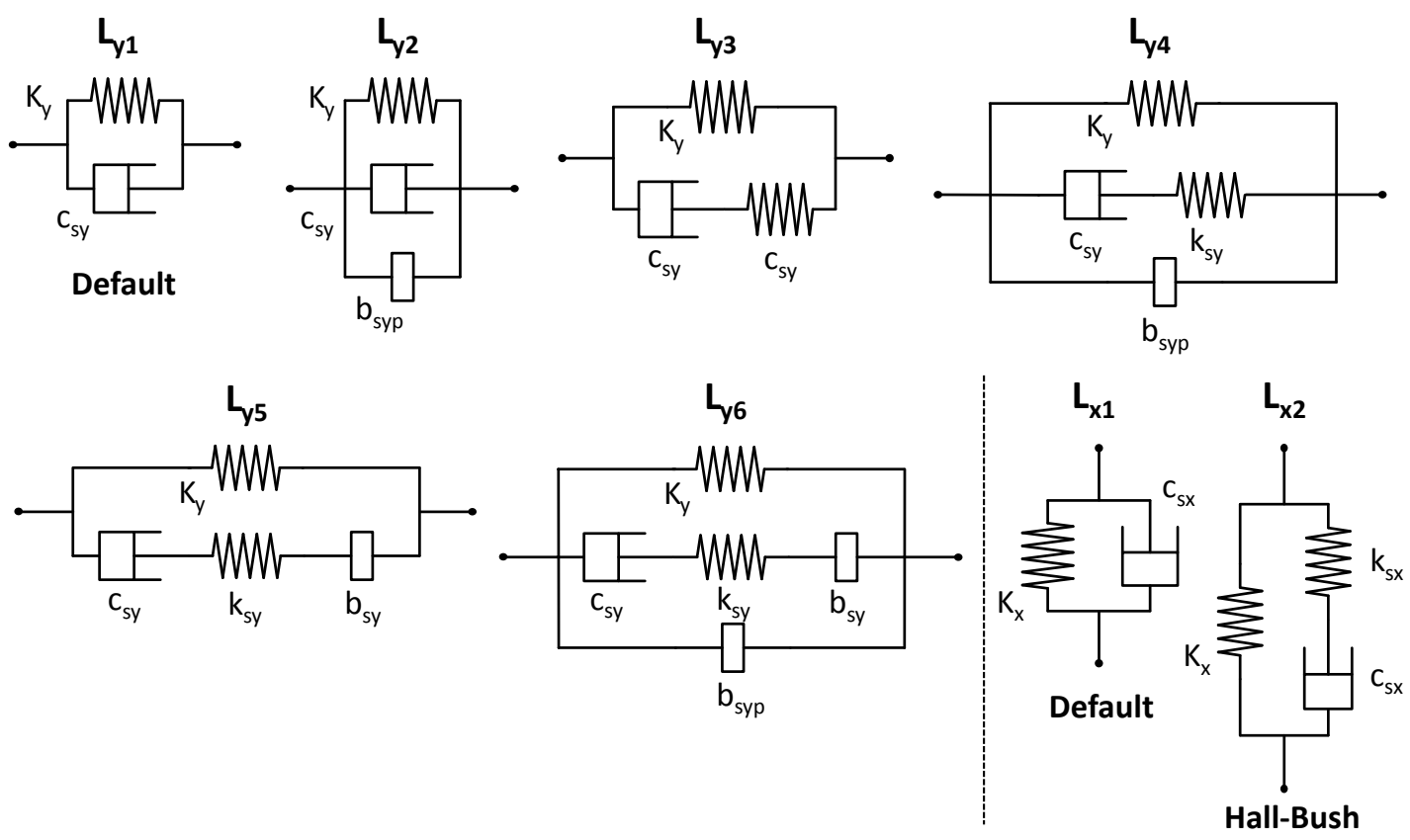

Figure 3. The six $L_{y i}(s)$ (lateral, investigated in [28] and [29]) and two $L_{x j}(s)$ (longitudinal) candidate layouts ( $L_{x 2}$ denotes the Hall-Bush structure which includes a static stiffness $K_{x}$ and dynamic stiffness $k_{s x}$ ).

Equations 2 - 7 can be re-arranged to form the state-space equation,

$$
s^{2} x=A(s) x+B u
$$

where $A(s)$ is the system matrix (detailed in Appendix A), capturing the internal dynamics, and $\mathrm{B}$ the matrix capturing external forcing dynamics. The input matrix, $u$, consists of either a timeseries of lateral track displacements (either from real track data or filtered white noise; see Section 3.1) for the passenger comfort case, or ramped timeseries of cant angle and radius of curvature for the curving performance case (see Figure 6). The size of matrix B depends on the inputs involved in the analysis. Passenger comfort assessment is performed on a nominally straight track, but with some lateral irregularities, resulting in a B matrix of, 


$$
B_{p}=\left[\begin{array}{cc}
0 & 0 \\
\frac{-2 f_{11} \lambda l_{w y}}{r_{0} m_{w}} & 0 \\
0 & 0 \\
0 & \frac{-2 f_{11} \lambda l_{w y}}{r_{0} m_{w}} \\
0 & 0 \\
0 & 0
\end{array}\right]
$$

where the columns relate respectively to the lateral track displacements $\hat{y}_{t 1}$ and $\hat{y}_{t 2}$. However, when assessing curving performance, it is assumed that these irregularities are negligible (similar to the analysis in $[28,29,31]$ ), as the steady-state lateral vehicle displacement is the primary concern. The inputs now become the track's cant angle and radius of curvature, leading to a $B$ matrix of

$$
B_{c}=\left[\begin{array}{cccc}
V^{2} & -g & 0 & 0 \\
\hline \frac{2\left(f_{11} l_{w y}^{2}+K_{x} L_{w x} l_{x}^{2}\right)}{I w} & 0 & 0 & 0 \\
0 & 0 & V^{2} & -g \\
0 & 0 & \frac{2\left(f_{11} l_{w y}^{2}-K_{x} L_{w x} l_{x}^{2}\right)}{I w} & 0 \\
V^{2} / 2 & -g / 2 & V^{2} / 2 & -g / 2 \\
\frac{-2 K_{x} L_{w x} l_{x}^{2}}{I v} & 0 & \frac{2 K_{x} L_{w x} l_{x}^{2}}{I v} & 0
\end{array}\right]
$$

with the columns respectively relating to the inputs: $R_{1}^{-1}, \theta_{c 1}, R_{2}^{-1}$ and $\theta_{c 2}$. The resulting transfer function,

$$
H_{\omega}=\left(s^{2} I-A(s)\right)^{-1} B
$$

in which $I$ denotes the 6 by 6 identity matrix, can be obtained and employed in MATLAB $^{\circledR}$ and Simulink ${ }^{\circledR}$ to calculate resulting displacements, velocities and accelerations of all six states.

\section{Assessment of Passenger Comfort and Track Wear}

This section introduces the techniques used in this paper to assess the vehicle's passenger comfort and track wear under straight running and curving conditions respectively.

\subsection{Assessing passenger comfort}

The Mean Comfort Standard Method, defined in EN 12299:2009 [32] is nominally used to assess a vehicle's passenger comfort. This method uses the 95th percentaile of frequency weighted Root Mean Square (RMS) carbody accelerations and is used as a standard when assessing passenger comfort on real vehicles with the use of accelerometers positioned on seats [33]. This paper, however, focuses on the relative benefits that the inerter can bring 
to railway vehicles, and as a simplified model is being used, comparisons with other more relistic models becomes less of an issue, and therefore the RMS lateral carbody acceleration is used as a measure of passenger comfort. This is in line with previous studies $[4,25,29,34]$. $J_{5}$ represents the passenger comfort cost function:

$$
J_{5}=\sqrt{\int_{0}^{\infty}\left|A_{c}(t)\right|^{2} d t} .
$$

$J$ represents RMS acceleration, subscript 5 the fifth state (carbody), and $A_{c}(t)$ is a timeseries of the resulting lateral carbody acceleration when the model is subject to track irregularities, simulating defects such as manufacturing faults and heat expansion and contraction variations. These irregularities have been simulated using filtered white noise in the frequency domain [25, 29], using techniques developed in [35]. This research however, to reflect real-life track conditions, utilises data taken from real sets of track, $5 \mathrm{~km}$ in length. The two sets of lateral track displacement data with rated velocities of $110 \mathrm{kph}$ and $160 \mathrm{kph}$ are respectively defined as Track110 and Track160, and with the knowledge of the vehicle's forward velocity, $V$, timeseries of these tracks can be obtained and defined as the inputs $\hat{y}_{t 1}$ and $\hat{y}_{t 2}$, respectively for the front and rear wheelsets. A time delay of:

$$
T_{d}=\frac{2 l_{w x}}{V}
$$

is used in the calculation of these timeseries.

Optimisations of parameters within each $L_{y i}(s)$ layout can now be performed with the aim of minimising $J_{5}$. Note that no longitudinal suspension optimisation is performed at this stage. A Simulink ${ }^{\circledR}$ model with the Track110 and Track160 timeseries as inputs is used to calculate $J_{5}$, and the static lateral stiffness, $K_{y}$ is fixed at it's nominal value given in Table 1, with each of the other $L_{y i}(s)$ network parameters being optimised over, with a non-negative constraint. The results for the Track110 and Track160 cases are shown in Tables 2 and 3 respectively, and summarised in Figure 4. The default operational vehicle velocity, $V_{o p}$, is used for both Track110 and Track160 cases. The default layout of the lateral suspension is that of $L_{y 1}$, and therefore the first row in Tables 2 and 3 represent baseline acceleration values, while the third column represents percentage improvements from these values.

\begin{tabular}{|c|c|c|c|c|c|c|}
\hline Layout & $\begin{array}{l}\text { Minimised } \\
J_{5}\left(m / s^{2}\right)\end{array}$ & $\begin{array}{c}J_{5} \text { reduction } \\
(\%)\end{array}$ & $\begin{array}{l}\text { Parameter values } \\
(\mathrm{N} / \mathrm{m}, \mathrm{Ns} / \mathrm{m}, \mathrm{kg})\end{array}$ & & & \\
\hline$L_{u 1}$ & 0.1335 & - & & $c_{s y}=1.51 \times 10^{4}$ & & \\
\hline$L_{y 2}$ & 0.1201 & 10.0 & & $c_{s y}=1.37 \times 10^{4}$ & & $b_{\text {syp }}=5.03 \times 10^{2}$ \\
\hline$L_{y 3}$ & 0.1335 & 0.0 & $k_{s y}=\infty$ & $c_{s y}=1.51 \times 10^{4}$ & & \\
\hline$L_{y 4}$ & 0.0934 & 30.0 & $k_{s y}=4.24 \times 10^{5}$ & $c_{s y}=3.82 \times 10^{4}$ & & $b_{\text {syp }}=1.13 \times 10^{3}$ \\
\hline$L_{y 5}$ & 0.1302 & 2.5 & $k_{s y}=\infty$ & $c_{s y}=1.54 \times 10^{4}$ & $b_{s y}=8.93 \times 10^{3}$ & \\
\hline$L_{y 6}$ & 0.0753 & 43.6 & $k_{s y}=3.40 \times 10^{5}$ & $c_{s y}=6.02 \times 10^{4}$ & $b_{s y}=7.70 \times 10^{3}$ & $b_{\text {syp }}=1.16 \times 10^{3}$ \\
\hline
\end{tabular}

Table 2. Optimisation results using Track110

From Tables 2 and 3 it can be seen that the series spring within configuration $L_{y 3}$ has no compliance, resulting in the RMS acceleration remaining at its default, $L_{y 1}$ value. A similar phenomenon occurs in $L_{y 5}$ and the inclusion of a series inerter does little to reduce 
Table 3. Optimisation results using Track160

\begin{tabular}{|c|c|c|c|c|c|c|}
\hline Layout & $\begin{array}{l}\text { Minimised } \\
J_{5}\left(\mathrm{~m} / \mathrm{s}^{2}\right) \\
\end{array}$ & $\begin{array}{c}J_{5} \text { reduction } \\
(\%)\end{array}$ & $\begin{array}{l}\text { Parameter values } \\
(\mathrm{N} / \mathrm{m}, \mathrm{Ns} / \mathrm{m}, \mathrm{kg})\end{array}$ & & & \\
\hline$L_{y 1}$ & 0.1091 & - & & $c_{s y}=1.51 \times 10^{4}$ & & \\
\hline$L_{y 2}$ & 0.1002 & 8.2 & & $c_{s y}=1.42 \times 10^{4}$ & & $b_{\text {syp }}=4.53 \times 10^{2}$ \\
\hline$L_{y 3}$ & 0.1091 & 0.0 & $k_{s y}=\infty$ & $c_{s y}=1.51 \times 10^{4}$ & & \\
\hline$L_{y 4}$ & 0.0748 & 31.4 & $k_{s y}=4.28 \times 10^{5}$ & $c_{s y}=4.20 \times 10^{4}$ & & $b_{\text {syp }}=1.13 \times 10^{3}$ \\
\hline$L_{y 5}$ & 0.1077 & 1.3 & $k_{s y}=\infty$ & $c_{s y}=1.56 \times 10^{4}$ & $b_{s y}=1.27 \times 10^{4}$ & \\
\hline$L_{y 6}$ & 0.0592 & 45.7 & $k_{s y}=2.92 \times 10^{5}$ & $c_{s y}=5.03 \times 10^{4}$ & $b_{s y}=6.42 \times 10^{3}$ & $b_{\text {syp }}=1.03 \times 10^{3}$ \\
\hline
\end{tabular}

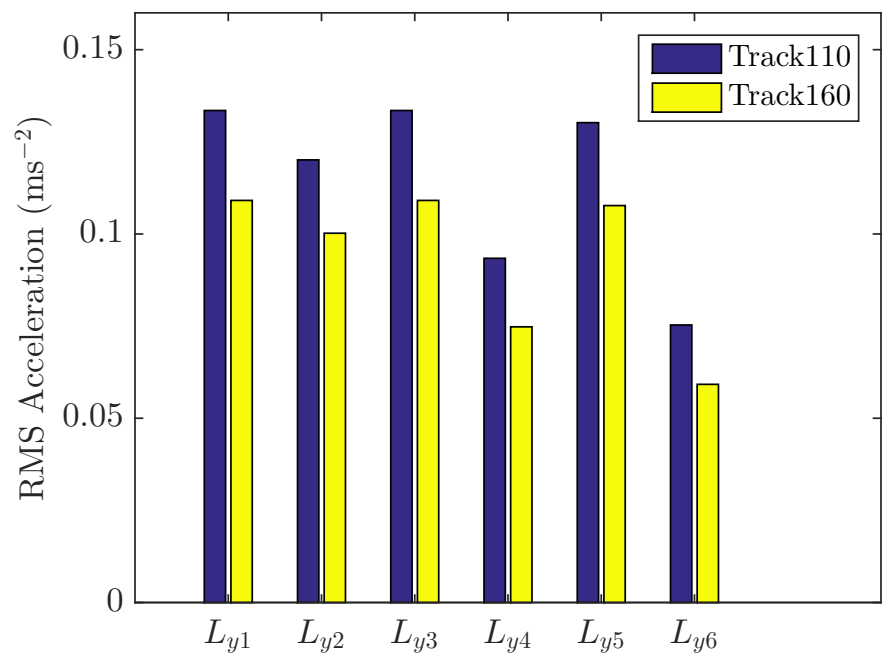

Figure 4. Bar chart representing the optimised RMS carbody acceleration values for Track110 and Track160, at an vehicle operation speed of $V_{o p}$.

the RMS acceleration, as it can be calculated that the newly introduced break frequency remains high when compared with the carbody oscillation frequencies. Improvements in $J_{5}$ of $0 \%$ and $1.3 \%$ for configurations $L_{y 3}$ and $L_{y 5}$ respectively are contrasted with those for $L_{y 2}, L_{y 4}$ and $L_{y 6}$, respectively $8.2 \%, 31.4 \%$ and $45.7 \%$. Track160, having a higher rated velocity than Track110, is comprised of less extensive lateral irregularities and hence produces a lower $J_{5}$ with similar trends; see Figure 4.

Figure 5 shows how the RMS carbody acceleration varies with an increase in vehicle velocity for the six lateral suspension configurations and for Track110 and Track160. For each velocity value, the same configurations are used to obtain the acceleration value. The vertical dashed line indicates the optimisation velocity, $V_{o p}$, and the RMS accelerations here correspond with the values shown in Figure 4. It can be seen that, for both plots, $L_{y 6}$ in general is the most optimum layout. Only in the intermediate region between $12 \mathrm{~ms}^{-1}$ and $21 \mathrm{~ms}^{-1}$ is $L_{y 6}$ not only sub-optimum, but the most detrimental to the RMS acceleration, however in reality vehicles will spend little time at this velocity. It is worth mentioning that the $L_{y 4}$ and $L_{y 6}$ cases exhibit an increase in RMS acceleration speeds above $V_{o p}$ (however as the vehicle is not designed to travel above this speed, this is not a concern).

The optimisation data described above matches well with the previous work in [25]. For example, similar trends can be seen when comparing Tables 2 and 3, and Figure 6 in [25] to receptively Tables 2 and 3, and Figure 5 in this paper. Confidence can be gained therefore that a valid passenger comfort assessment has been introduced. 


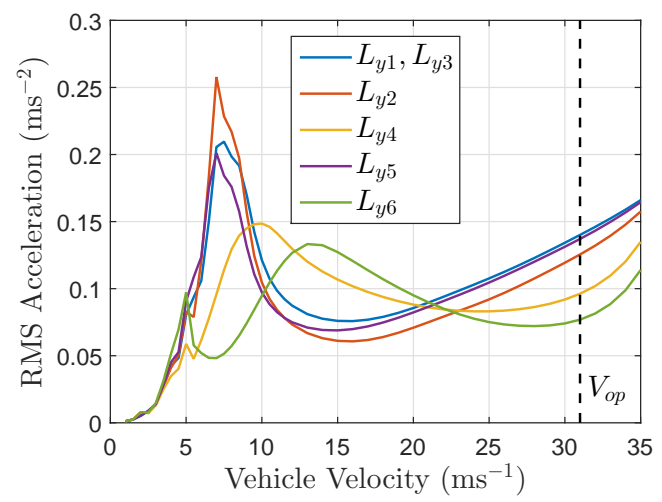

(a) Track110

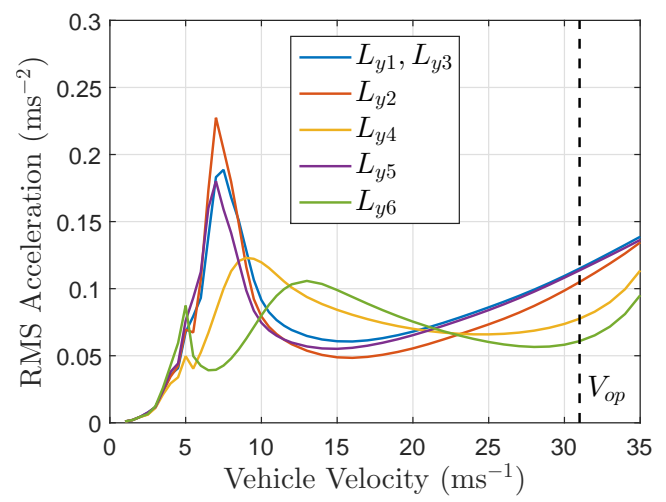

(b) Track160

Figure 5. RMS carbody acceleration vs vehicle velocity for both sets of real track data, with the vehicle operation velocity, $V_{o p}$, highlighted.

\subsection{Assessing curving performance}

The curving performance of the railway vehicle model is assessed by quantifying the energy lost at the contact point, $T_{\gamma}$. This industrial parameter captures the detrimental effects on the wheels and rails produced by curving. As discussed in Section 2, the $6 \times 4 \mathrm{~B}$ matrix (Equation 17) is used for curving analysis, with the system inputs $R_{1}{ }^{-1}, \theta_{c 1}, R_{2}{ }^{-1}$ and $\theta_{c 2}$. These take the form of ramps in the time domain with a 1 second transition period when entering and leaving a curve (using the same input method described in [28]), and an appropriate time delay between wheelsets based on the vehicle speed and wheelset separation distance (see Figure 6 and Equation 20).

Appendix B details the derivation of $T_{\gamma}$,

$$
T_{\gamma 1 l}=F_{x 1 l} v_{x 1 l}+F_{y 1 l} v_{y 1 l},
$$

for the front wheelset's left wheel $[1,36] . F$ denotes creep force, and $v$ creepage, while subscripts $1, l, x$ and $y$ represent respectively the wheelset number (front), the left wheel, and the lateral and longitudinal directions. When presenting data in Sections 3 and 4, the mean value of $T_{\gamma}$ over all four wheels is used as a measure of track wear; the values for the other wheels are determined using exactly the same approach. The value of $T_{\gamma}$ depends on the square of both the lateral and longitudinal creepages. This analysis assumes clean, dry conditions with a coefficient of friction value of $\mu=0.6$, and a linear relationship between creepage and creep force [36].

Figures 7(a)-(f) display wheelset displacements, carbody accelerations, and $T_{\gamma}$ values when the yaw stiffness is at its default value of $K_{x}=1 \times 10^{6} \mathrm{Nm}^{-1}$, and $K_{x}=$ $3 \times 10^{6} \mathrm{Nm}^{-1}$, using the default, $L_{y 1}$ lateral suspension configuration (See Table 1 for parameter values). The discrepancy between the front and rear wheelset lateral displacements in Figures 7(a) and (b) arises from the radius of curvature and the yaw stiffness causing an equal and opposite net moment on the wheelsets [28, 29]. Assessing the transient carbody acceleration occurring in both of the three second periods immediately after the start of each transition (see Figures 7(c) and (d)), it can be seen that the acceleration here is negligible when compared with the optimised accelerations found from the analysis in Section 3.1. For example, the transient RMS acceleration of $0.0058 \mathrm{~ms}^{-2}$, seen between the vertical dashed lines in Figure $7(\mathrm{~d})$, is $9.7 \%$ of the lowest acceleration found in Section 3.1. This value rises to only $16.5 \%$ for the worst case transient acceleration 


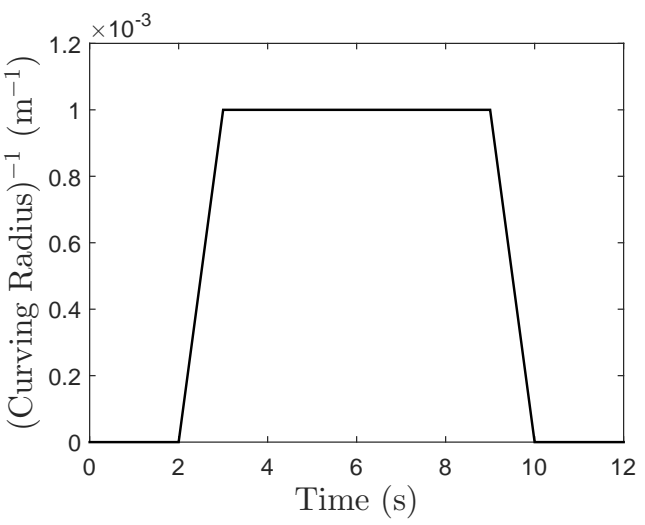

(a)

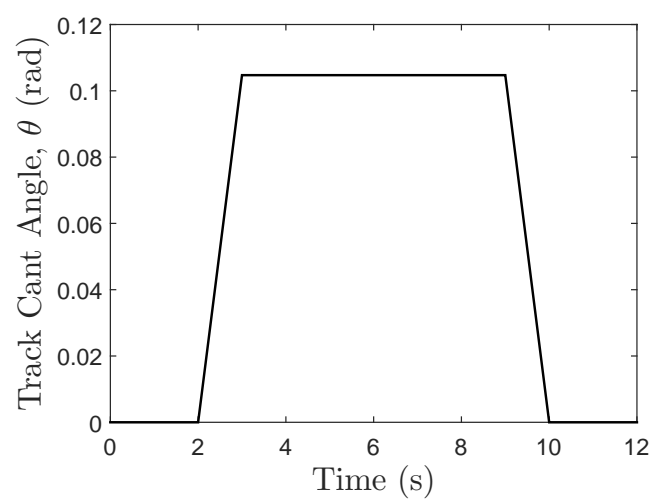

(b)

Figure 6. Ramped inputs of the inverse of the curving radius $\left(R_{1}^{-1}\right)$, and the track's cant angle $\left(\theta_{c 1}\right)$, both at wheelset 1 . The same inputs occur at wheelset 2 but including the time delay, $T_{d}$.

scenario. The subsequent track wear analysis therefore does not put any emphasis on acceleration induced by curving. Figures $7(\mathrm{e})$ and (f) show that the wheelsets remain in equilibrium due to the higher wheel-rail contact forces on the front wheel, and note that $T_{\gamma}$ at the front and rear right wheel is predicted to be identical to that of the front and rear left wheel respectively. This is due to the symmetric vehicle set-up and perfect conical nature of the wheels resulting in identical absolute lateral and longitudinal creepage magnitudes (see Equations B1 and B2 in Appendix B).

This section has established $T_{\gamma}$ as the measure of track wear and, it can be concluded that the assessment of track wear produces intuitive results in terms of wheelset displacement and contact patch forces, which are in accordance with [28].

\section{The Trade-Off Between Passenger Comfort and Track Wear}

Figures $7(\mathrm{e})$ and (f) help to demonstrate how $T_{\gamma}$ grows nonlinearly with increasing yaw stiffness. This is due to it's squared creepage terms which can be interpreted from Equations B9 and B10 in Appendix B. $T_{\gamma}$ is found to be highly dependent on the yaw stiffness, due to increasing $K_{x}$ highly correlating with an increasing steady state curving displacement, and hence larger longitudinal creep forces. Simply including more complicated, optimised inerter-based structures in the lateral suspension therefore does not directly reduce $T_{\gamma}$, although in most cases the passenger comfort is significantly improved. This is captured in the trade-off plots shown in Figures 8(a) and (b), which consider optimisations for increasing passenger comfort using a range of yaw stiffnesses for both Track110 (Figure 8(a)) and Track160 (Figure 8(b)) inputs.

Each plot in Figure 8 is generated as follows: firstly, optimisations for increasing passenger comfort take place using the baseline suspension, layout $L_{y 1}$ at a yaw stiffness $\left(K_{x}\right)$ value of $1 \times 10^{6} \mathrm{Nm}^{-1} . K_{x}$ is increased in steps of $0.5 \times 10^{6} \mathrm{Nm}^{-1}$ to $4.5 \times 10^{6} \mathrm{Nm}^{-1}$ to produce the black solid line. To aid comparison across the layouts, the points on each curve corresponding to a fixed $K_{x}$ value are joined by dotted lines - these are near horizontal highlighting that the lateral suspension improvements do not impact on the track wear. The lowest dotted line is for $K_{x}=1 \times 10^{6} \mathrm{Nm}^{-1}$ and the highest for $K_{x}=$ $4.5 \times 10^{6} \mathrm{Nm}^{-1}$, with increments of $0.5 \times 10^{6} \mathrm{Nm}^{-1}$ in between. Note that for this set of optimisations, the damper $c_{s x}$ of $L_{x 1}$ is fixed to its nominal value shown in Table 1 . This 


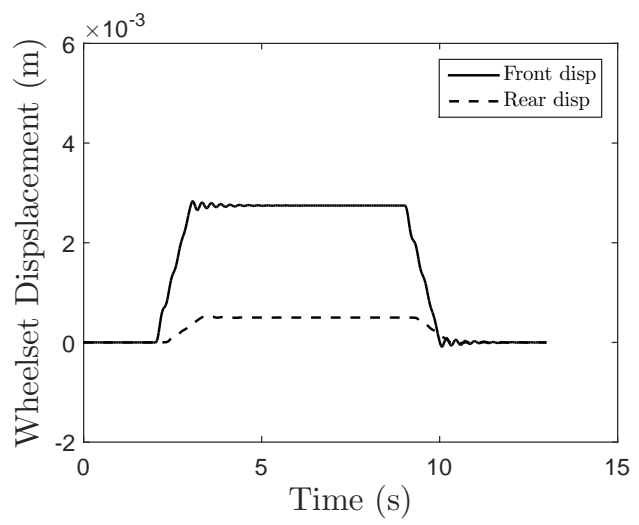

(a) $K_{x}=1 \times 10^{6} \mathrm{Nm}^{-1}$

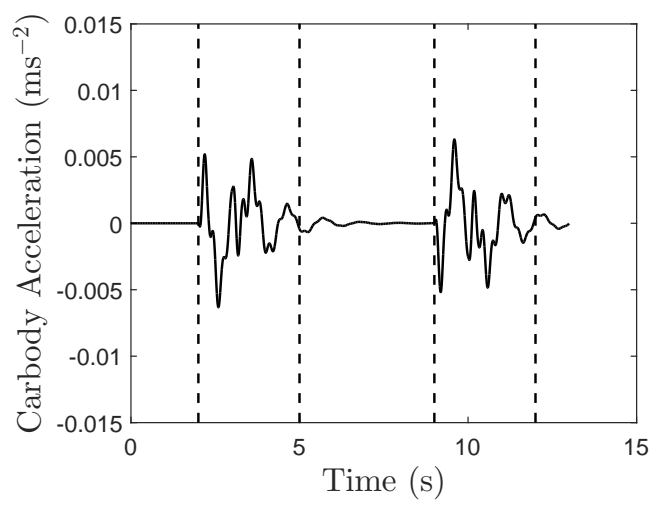

(c) $K_{x}=1 \times 10^{6} \mathrm{Nm}^{-1}$

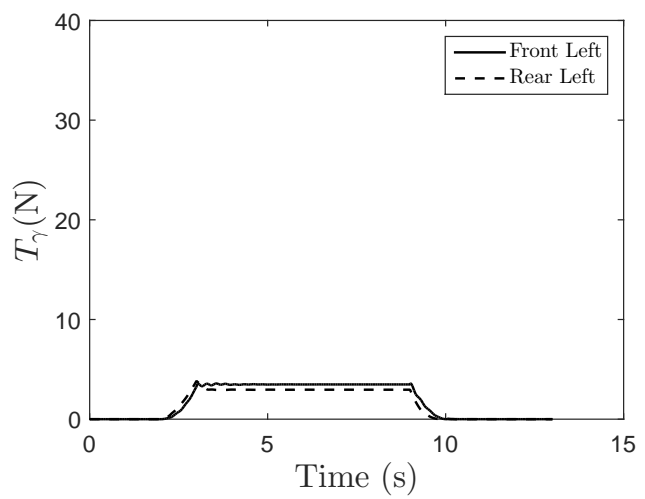

(e) $K_{x}=1 \times 10^{6} \mathrm{Nm}^{-1}$

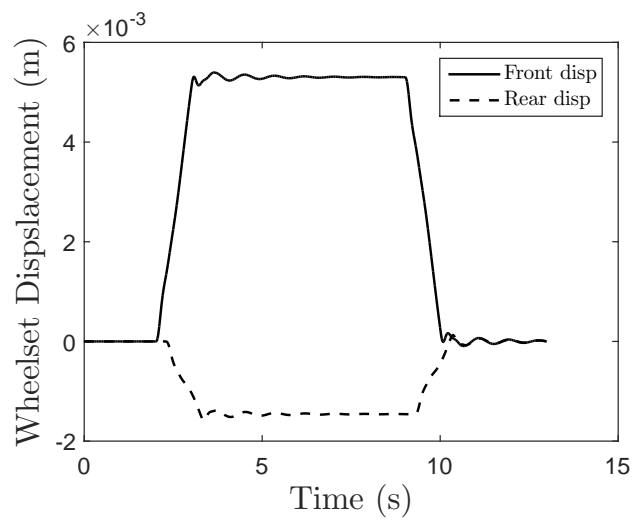

(b) $K_{x}=3 \times 10^{6} \mathrm{Nm}^{-1}$

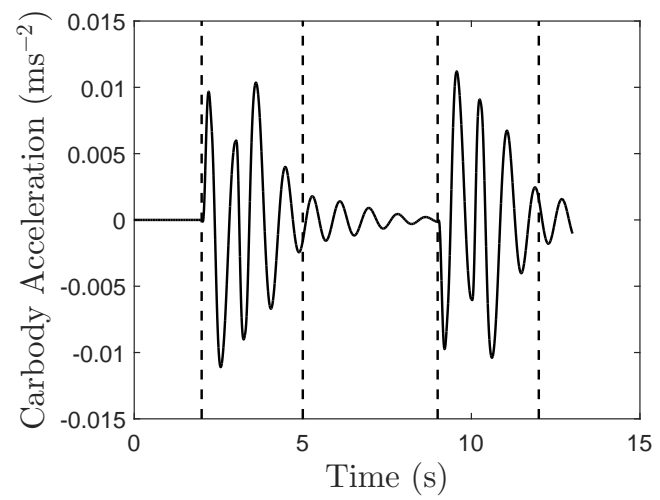

(d) $K_{x}=3 \times 10^{6} \mathrm{Nm}^{-1}$

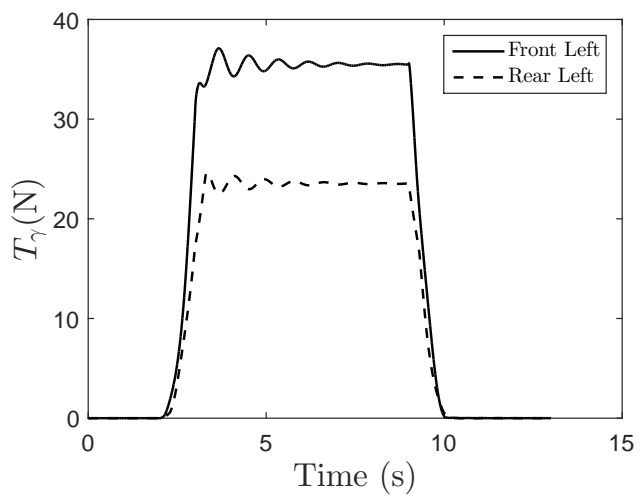

(f) $K_{x}=3 \times 10^{6} \mathrm{Nm}^{-1}$

Figure 7. Front and rear wheelset displacement, carbody acceleration and $T_{\gamma}$ vs time under curving conditions, using default $L_{y 1}$ and $L_{x 1}$ lateral and longitudinal suspension configurations, and at two different yaw stiffness values. The simulation velocity remains at $V_{o p}$.

is due to the performance being insensitive to its value within a large range, and also its variation forms a subset of the Hall-Bush optimisation which is discussed later on in this section.

The solid black curve, representing the default lateral suspension $\left(L_{y 1}\right)$, shows the trade-off between straight running and curving performance, as increasing $K_{x}$ inherently increases $T_{\gamma}$ yet allows the RMS acceleration to reduce, and vice versa. It is found 


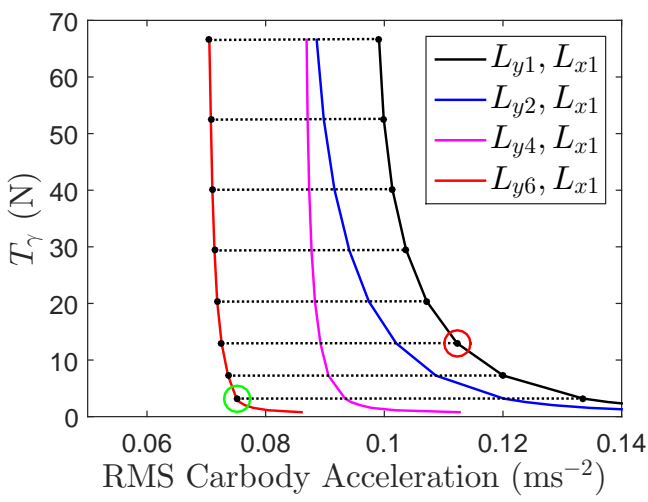

(a) Track110

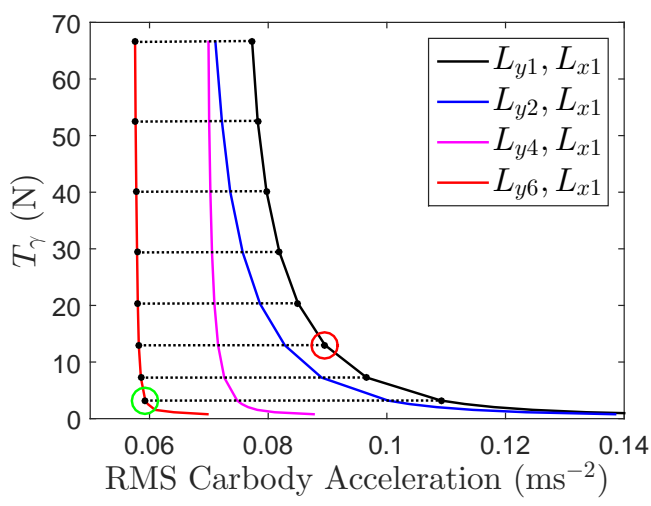

(b) Track160

Figure 8. Trade-off plots showing $T_{\gamma}$ vs optimised RMS carbody acceleration for values of $K_{x}$ varying from $0.5 \times 10^{6} \mathrm{Nm}^{-1}$ to $4.5 \times 10^{6} \mathrm{Nm}^{-1}$, with the $L_{y 1}, L_{y 2}, L_{y 4}$ and $L_{y 6}$ lateral suspension configurations, and the default $L_{x 1}$ longitudinal configuration (the coloured circles indicate example improvements for both track wear and passenger comfort).

that when the three beneficial layouts identified in Sub-section 3.1 are employed, and the system re-optimised, this trade-off, although still in existence, is improved as the carbody accelerations are reduced for any given $T_{\gamma}$. Consider the Track110 case, it can be seen that for a given layout it is not possible to improve both $T_{\gamma}$ and RMS acceleration. However through the use of a more complex layout this can be achieved; for example, at the point on the default $L_{y 1}$ curve in Figure $8(\mathrm{a})$, where $K_{x}=2 \times 10^{6} \mathrm{Nm}^{-1}$, indicated by the red circle, RMS acceleration $=0.112 \mathrm{~ms}^{-2}$ and $T_{\gamma}=13 \mathrm{~N}$. If instead the $L_{y 6}$ layout is used, and the yaw stiffness is reduced to $1 \times 10^{6} \mathrm{Nm}^{-1}$ (see the green circle), values of $0.075 \mathrm{~ms}^{-2}$ and $3.2 \mathrm{~N}$ can be achieved, respectively providing improvements of $33 \%$ and $75 \%$. Similar benefits can be seen with the other inerter-based layouts, and it can be concluded therefore that passenger comfort can be improved and track wear reduced concurrently by employing inerter-based configurations in the lateral suspension, allowing a reduction of the yaw stiffness. Note the same trends are exhibited with the Track160 analysis.

Now consider including the Hall-Bush as the longitudinal suspension layout, $L_{x 2}$ in Figure 3, rather than the default $L_{x 1}$ layout. The Hall-Bush structure is widely used in the railway industry [5] and consists of a high stiffness dynamic spring $\left(k_{s x}\right)$ in series with a damper, and the lower parallel static yaw stiffness $\left(K_{x}\right)$. This optimisable series stiffness allows for an improved passenger comfort over the conventional $L_{x 1}$ layout. This is shown in Figure 9 for the case where the lateral suspension considered is $L_{y 1}$. Note here that for the Hall-Bush case, a more general approach is taken, with $k_{s x}$ and $c_{s x}$ being optimised in addition to the lateral suspension parameters. Here the solid black line is repeated, to aid comparison, and the dashed line shows the improvement in carbody acceleration achievable using the Hall-Bush. Again, altering the yaw stiffness only affects the track wear. As an example of the improvements that are observed here, re-evaluating the changes in track wear and passenger comfort from the red to green circle in Figure 9(a), improvements in passenger comfort and track wear of $21 \%$ and $75 \%$ respectively are identified with the inclusion of the Hall-Bush.

Finally, Figure 10 extends the analysis including the longitudinal Hall-Bush to lateral layouts $L_{y 2}$ and $L_{y 6}$. Layout $L_{y 4}$ is not shown as its curve is found to converge quickly to that of $L_{y 2}$ with increasing values of $K_{x}$. A passenger comfort improvement of $40 \%$ can be achieved when compared to the default non Hall-Bush and $L_{y 1}$ set-up (solid 


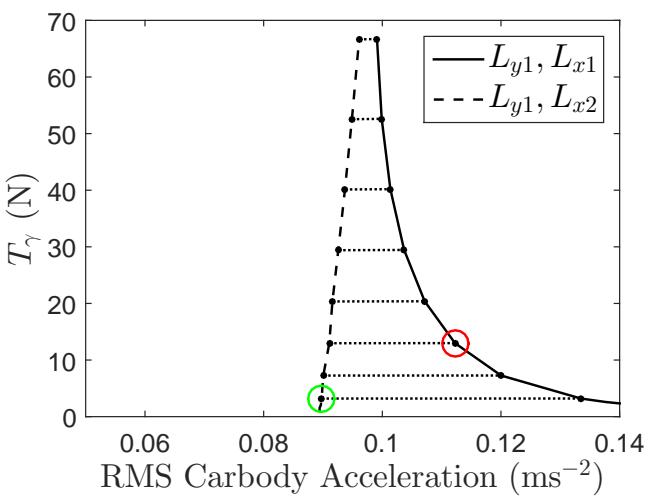

(a) Track110

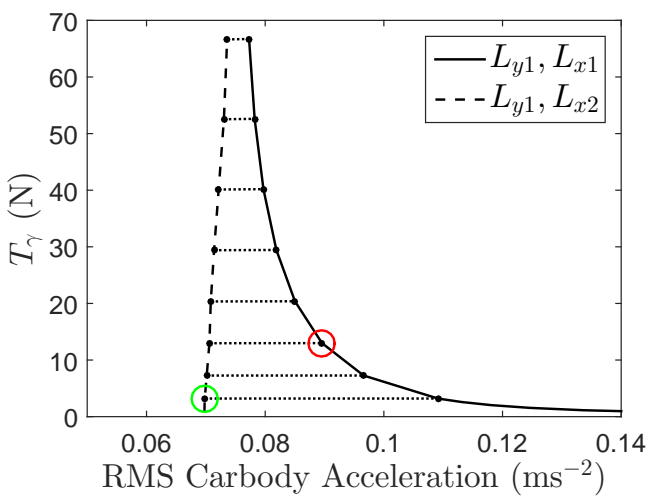

(b) Track160

Figure 9. Trade-off plots showing $T_{\gamma}$ vs optimised RMS carbody acceleration for values of $K_{x}$ varying from $0.5 \times 10^{6} \mathrm{Nm}^{-1}$ to $4.5 \times 10^{6} \mathrm{Nm}^{-1}$, with the optimised default $L_{y 1}$ lateral and both the default $L_{x 1}$ and Hall Bush $L_{x 2}$ longitudinal suspension configurations (the coloured circles indicate example improvements for both track wear and passenger comfort).

black line). Another important consideration is the extent to which inerter-based lateral suspension layouts improve passenger comfort over the use of the Hall-Bush structure and $L_{y 1}$. Comparing the green circles in Figures $9(\mathrm{a})$ and 10(a), a passenger comfort improvement of $25 \%$ is achievable in this case.

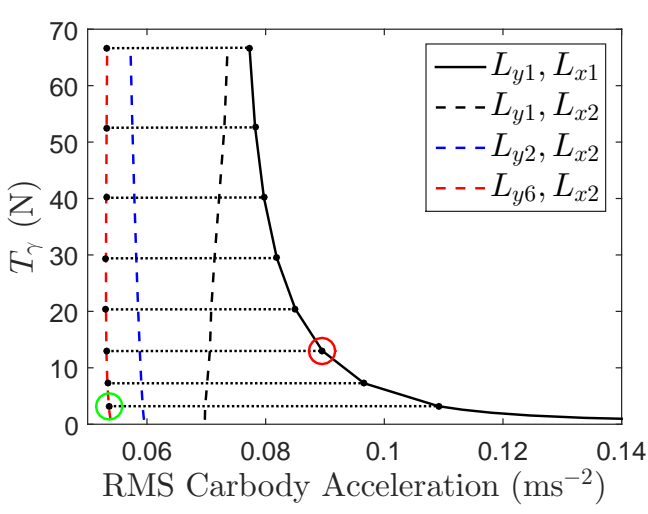

(a) Track110

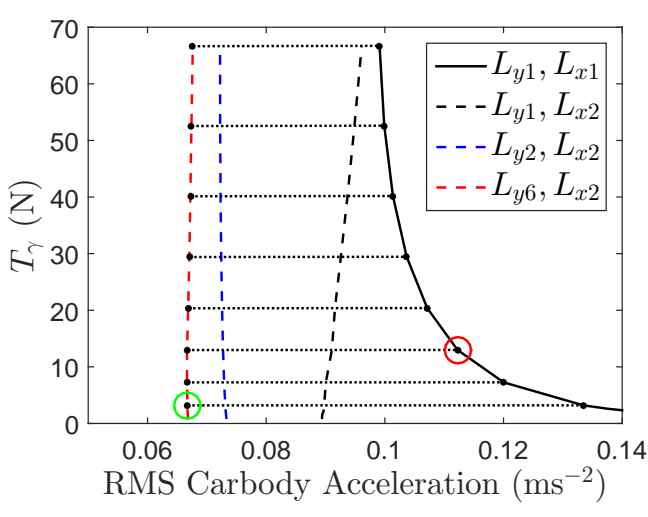

(b) Track160

Figure 10. Trade-off plots showing $T_{\gamma}$ vs optimised RMS carbody acceleration for values of $K_{x}$ varying from $0.5 \times 10^{6} \mathrm{Nm}^{-1}$ to $4.5 \times 10^{6} \mathrm{Nm}^{-1}$, comparing the fully optimised $L_{y 2}$ and $L_{y 6}$ configurations combined with $L_{x 2}$ combinations with the original optimised default $L_{y 1}$ and $L_{x 1}$ combination (the coloured circles indicate example track wear and passenger comfort improvements).

Analysing how the optimum suspension parameter values vary with yaw stiffness has the potential to yield look-up plots where appropriate parameters may be chosen according to the amount of track wear and passenger comfort permissible. To this end, plots of how the suspension parameter values vary with yaw stiffness can be found in Figures C1 and C2 in Appendix C. The non-smooth nature of these plots is most likely due to the patternsearch optimisation homing in on local minima.

A sensitivity analysis using a half creep model (where the wheel-rail coefficient of friction has been halved to 0.3 ) has been performed for layouts $L_{y 1}$ and $L_{y 2}$ (See Figure 11). The conclusion of this is that whilst the values of $T_{\gamma}$ and RMS carbody acceleration 


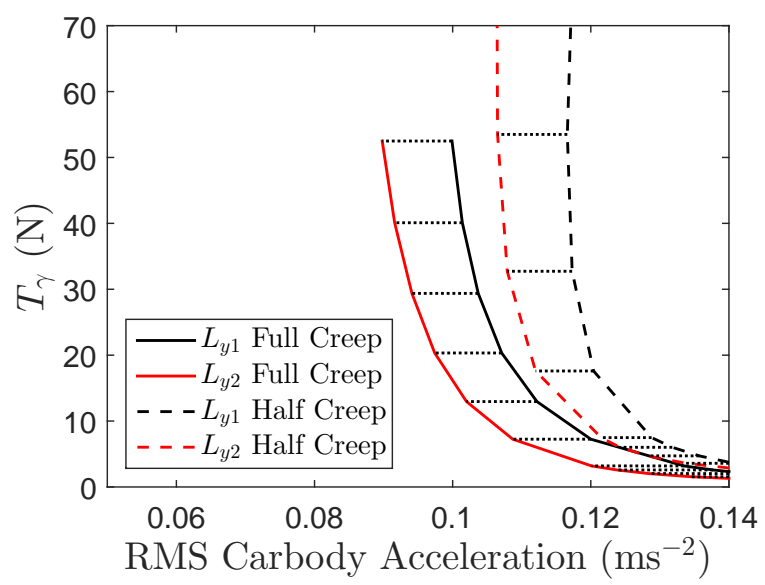

Figure 11. Non Hall-Bush trade-off plots showing $T_{\gamma}$ vs optimised RMS carbody acceleration, for configurations $L_{y 1}$ and $L_{y 2}$, comparing full creep and half creep conditions

have changed, the trade-off between them remains, and passenger comfort benefits can still be obtained with the use of inertance-integrated lateral suspension layouts.

A summarising example of the benefits that inerter-based lateral suspensions can bring to a two-axle railway vehicle assessed on Track110 is detailed as follows: combined with a yaw stiffness reduction of $50 \%$ (from $2 \times 10^{6} \mathrm{Nm}^{-1}$ to $1 \times 10^{6} \mathrm{Nm}^{-1}$, resulting in a $T_{\gamma}$ improvement of $75 \%$ ) the implementation of an $L_{y 2}$ lateral layout yields a passenger comfort improvement of $35 \%$ compared to the default $L_{x 1}$ layout, and $18 \%$ when compared with the optimum default lateral layout plus Hall-Bush setup. These percentage improvements can be increased to $40 \%$ and $25 \%$ respectively when the more complex $L_{y 6}$ layout is used.

\section{Conclusions}

This paper has shown that the incorporation and optimisation of inerter-based structures in the lateral suspension of railway vehicles can concurrently improve passenger comfort and decrease track wear. Further analysis demonstrates that inerter-based configurations in the lateral suspension provide added benefits when an optimised Hall-Bush configuration, is used as the longitudinal suspension. The two-axle model used quantifies track wear using the energy lost at the wheel-rail contact patch, $T_{\gamma}$, when the vehicle is in a curve, and assesses passenger comfort in straight running conditions using the RMS acceleration of the carbody. Optimisations for passenger comfort improvement have been performed on five inerter-based layouts and it has been found that layout $L_{y 6}$, which includes both a series and parallel inerter, can achieve a RMS acceleration reduction, and hence a passenger comfort improvement of $43 \%$. Curving analysis concludes that although the use of inerters in the lateral suspension cannot directly reduce $T_{\gamma}$, it enables the yaw stiffness to be reduced whilst also reducing RMS acceleration during straight running, which in turn allows for a reduction in $T_{\gamma}$. Reducing the yaw stiffness by $50 \%$ and implementing the most beneficial inerter-based layout in the lateral suspension yields a $T_{\gamma}$ reduction of $75 \%$ and a passenger comfort improvement of $33 \%$, and combined with the longitudinal Hall-Bush, the passenger comfort improvement rises to $40 \%$. When comparing the most beneficial inerter-based layout to the default lateral layout, both combined with the Hall-Bush structure in the longitudinal suspension, a passenger comfort improvement of $25 \%$ can be achieved. The results from this simplified model 
show highly promising performance benefits. The next step in developing this concept is to validate the findings using a more sophisticated model such as the ones commercially available using VAMPIRE.

\section{Funding}

The authors would like to thank the EPSRC (Grant References: EP/M507994/1 and EP/P013546/1) and the Royal Society (Grant Reference: IE151194) for funding this research.

\section{References}

[1] M. Burstow, "VTAC calculator: Guidance note for determining t $\gamma$ values," 2012. Available at https://cdn.networkrail.co.uk/wp-content/uploads/2016/12/VTAC-calculator-Guidancenote-for-determining-Tgamma-values.pdf.

[2] T. X. Mei and R. M. Goodall, "Practical strategies for controlling railway wheelsets with independently rotating wheels," Journal of Dynamic Systems, Measurement, and Control, vol. 125, pp. 354-360, 203.

[3] R. Goodall and T. X. Mei, "Mechatronic strategies for controlling railway wheelsets with independently rotating wheels," in 2001 IEEWASME International Conference on Advanced Intelligent Mechatronics Proceedings 6-12 July 2001 Como, Italy, pp. 225-230, 2001.

[4] T. X. Mei and R. M. Goodall, "Robust control for independently rotating wheelsets on a railway vehicle using practical sensors," IEEE Transactions on Control Systems Technology, vol. 9(4), pp. 599-607, 2001.

[5] J. Evans, "Application of the hall hydraulic radial arm bush to a $200 \mathrm{~km} / \mathrm{h}$ inter-city coach," in International Symposium on Dynamics of Vehicle on Road and Tracks, IAVSD, 2011.

[6] M. Smith, "Synthesis of mechanical networks: The inerter," IEEE Transactions on Automatic Control, vol. 47(10), pp. 1648-1662, 2002.

[7] B. Otto, "Synthesis of a finite two-terminal network whose driving-point impedance is a prescribed function of frequency," Journal of Mathematics and Physics, vol. 10, no. 1-4, pp. 191-236.

[8] M. C. Smith and F.-C. Wang, "Performance benefits in passive vehicle suspensions employing inerters," Vehicle System Dynamics, vol. 42, no. 4, pp. 235-257, 2004.

[9] I. F. Lazar, S. A. Neild, and D. J. Wagg, "Using an inerter-based device for structural vibration suppression," Earthquake Engineering Structural Dynamics, vol. 43, pp. 1129-1147, 2014.

[10] F.-C. Wang, C.-W. Chen, M.-K. Liao, and M.-F. Hong, "Performance analyses of building suspension control with inerters," 46th IEEE Conference on Decision and Control, 2007.

[11] S. Y. Zhang, J. Z. Jiang, and S. Neild, "Optimal configurations for a linear vibration suppression device in a multi-storey building," Structural Control and Health Monitoring, vol. 24, no. 3, pp. e1887-n/a, 2017. e1887 STC-16-0018.R2.

[12] F. Scheibe and M. Smith, "Analytical solutions for optimal ride comfort and tyre grip for passive vehicle suspensions," Vehicle System Dynamics, vol. 47(10), pp. 1229-1252, 2009.

[13] S. Evangelou, D. J. N. Limebeer, R. S. Sharp, and M. C. Smith, "An h infinity loop-shaping approach to steering control for high-performance motorcycles," Lecture Notes in Control and Information Sciences, vol. 329, pp. 257-275, 2006.

[14] J. Z. Jiang, M. Smith, and N. E. Houghton, "Experimental testing and modelling of a mechanical steering compensator," International Symposium on Communications, Control and Signal Processing, pp. 249-254, 2008.

[15] Y. Li, C. Howcroft, S. Neild, and J. Jiang, "Using continuation analysis to identify shimmysuppression devices for an aircraft main landing gear," Journal of Sound and Vibration, vol. 408, pp. 234-251, 112017.

[16] Y. Li, J. Jiang, and S. Neild, "Inerter-based configurations for main landing gear shimmy suppression," Journal of Aircraft, vol. 54, pp. 684-693, 32017.

[17] Y.-C. Chen, S.-Y. Wu, and F.-C. Wang, "Vibration control of a three-leg optical table by mechatronic inerter networks," SICE Annual Conference 2014, 2014. 
[18] M. Z. Q. Chen, C. Papageorgiou, F. Scheibe, F.-C. Wang, and M. C. Smith, "The missing mechanical circuit element," IEEE Circuits and Sytems Magazine, 2009.

[19] S. J. Swift, M. C. Smith, A. R. Glover, C. Papageorgiou, B. Gartner, and N. E. Houghton, "Design and modelling of a fluid inerter," International Journal of Control, vol. 86(11), pp. 2035-2051, 2013.

[20] R. Andrews, A. Duncan, T. Lewis, and E. Yang, "Design, manufacture and testing of fluid inerter devices," tech. rep., University of Bristol, 2015.

[21] X. Liu, J. Jiang, B. Titurus, A. Harrison, and D. McBryde, "Testing and modelling of the damping effects for fluid-based inerters," Procedia Engineering, vol. 199, pp. 435-440, 2017.

[22] F.-C. Wang, M.-F. Hong, and Y. C. Lin, "Designing and testing a hydraulic inerter," IMECHE Mechanical Engineering Science, vol. 225, pp. 66-72, 2010.

[23] F.-C. Wang, M.-R. Hsieh, and H.-J. Chen, "Stability and performance analysis of a full-train system with inerters," Vehicle System Dynamics, vol. 50, no. 4, pp. 545-571, 2012.

[24] F.-C. Wang and M.-K. Liao, "The lateral stability of train suspension systems employing inerters," Vehicle System Dynamics, vol. 48, no. 5, pp. 619-643, 2010.

[25] J. Z. Jiang, A. Z. Matamoros-Sanchez, R. M. Goodall, and M. C. Smith, "Passive suspensions incorporating inerters for railway vehicles," Vehicle System Dynamics: International Journal of Vehicle Mechanics and Mobility, vol. 50:sup1), pp. 263-276, 2012.

[26] A. Z. Matamoros-Sanchez and R. M. Goodaoll, "Applications of the inerter in railway vehicle suspension," in 2014 UKACC International Conference on Control (CONTROL), pp. 555-560, July 2014.

[27] A. Z. Matamoros-Sanchez and R. M. Goodall, "Novel mechatronic solutions incorporating inerters for railway vehicle vertical secondary suspensions," Vehicle System Dynamics, vol. 53, no. 2, pp. 113136, 2015.

[28] J. Jiang, T. Mei, and M. Smith, "Curving performance for railway vehicles with advanced passive suspensions," in 23rd International Symposium on Dynamics of Vehicle on Road and Tracks, IAVSD, 2013.

[29] J. Z. Jiang, A. Z. Matamoros-Sanchez, A. Zolotas, R. M. Goodall, and M. C. Smith, "Passive suspensions for ride quality improvement of two-axle railway vehicles," IMECHE: Journal of Rail and Rapid Transit, vol. 229(3), pp. 315-329, 2015.

[30] "Vampire help manual," tech. rep., DeltaRail Group Limited, 2016.

[31] T. Lewis, J. Jiang, S. Neild, C. Gong, and S. Iwnicki, "Improving ride comfort and trackwear of twoaxle railway vehicles using inerter-based lateral suspension layouts," Noise and Vibration Emerging Methods, 2018.

[32] B.-A. E. Standard, BS EN 12299:2009, Railway applications. Ride comfort for passengers. Measurement and evaluation. 2009.

[33] B. Kufver, R. Persson, and J. Wingren, "Certain aspects of the cen standard for the evaluation of ride comfort for rail passengers," pp. 605-614, 082010.

[34] A. C. Mellando, C. Casanueva, J. Vinolas, and J. G. Gimenez, "A lateral active suspension for conventional railway bogies," Vehicle System Dynamics, vol. January 2009, 2009.

[35] H. Li, Measuring Systems for Active Steering of Railway Vehicles. PhD thesis, Loughborough University, 2001.

[36] J. J. Kalker, "The computation of three-dimensional rolling contact with dry friction," International Journal for Numerical Methods in Engineering, vol. 14, no. 9, pp. 1293-1307, 1979. 


\section{Appendix A. The Laplace Equation System Matrix}

The matrix $A(s)$ from Equation 15 can be written as follows,

$$
\mathrm{A}(\mathrm{s})=\left[\begin{array}{cccccc}
A_{1} & \frac{2 f_{22}}{m_{w}} & 0 & 0 & \frac{2 s L_{y i}(s)}{m_{w}} & \frac{2 s L_{y i}(s) l_{w x}}{m_{w}} \\
\frac{2 f_{11} \lambda l_{w y}}{r_{0} I_{w}} & A_{2} & 0 & 0 & 0 & \frac{2 s L_{x j}(s) l_{x}^{2}}{I_{w}} \\
0 & 0 & A_{1} & \frac{2 f_{22}}{m_{w}} & \frac{2 s L_{y i}(s)}{m_{w}} & -\frac{2 s L_{y i}(s) l_{w x}}{m_{w}} \\
0 & 0 & -\frac{2 f_{11} \lambda l_{w y}}{r_{0} I_{w}} & A_{2} & 0 & \frac{2 s L_{x j}(s) l_{x}^{2}}{I_{w}} \\
\frac{2 s L_{y i}(s)}{m_{v}} & 0 & \frac{2 s L_{y i}(s)}{m_{v}} & 0 & -\frac{4 s L_{y i}(s)}{m_{v}} & 0 \\
\frac{2 s L_{y i}(s) l_{w x}}{I_{v}} & \frac{2 s L_{x j}(s) l_{x}^{2}}{I_{v}} & -\frac{2 s L_{y i}(s) l_{w x}}{I_{v}} & \frac{2 s L_{x j}(s) l_{x}^{2}}{I_{v}} & 0 & A_{3}
\end{array}\right]
$$

with substitutions,

$$
\begin{gathered}
A_{1}=-\frac{2 s L_{y i}(s)}{m_{w}}-\frac{2 s f_{22}}{V m_{w}}+\frac{2 \varepsilon}{l_{w y} m_{w}}\left(N-\frac{f_{23}}{r_{0}}\right) \\
A_{2}=-\frac{2 s L_{x j}(s) l_{x}^{2}}{I_{w}}-\frac{2 s f_{11} l_{w y}^{2}}{I_{w} V} \\
A_{3}=-\frac{4 s\left(L_{x j}(s) l_{x}^{2}+L_{y i}(s) l_{w x}^{2}\right)}{I_{v}}
\end{gathered}
$$

required, and all parameters detailed in Table 1.

\section{Appendix B. Derivation of $T_{\gamma}[1,30]$}

The longitudinal and lateral creepages, $v_{x 1 l}$ and $v_{y 1 l}$,

$$
\begin{gathered}
v_{x 1 l}=\frac{l_{w y} \dot{\theta_{w 1}}}{V}+\frac{\lambda y_{w 1}}{r_{0}}-\frac{l_{w y}}{R_{1}}, \\
v_{y 1 l}=\frac{y_{w 1}}{V}-\theta_{w 1},
\end{gathered}
$$

are used to calculate the relative velocity between the wheel and rail, and the spin creepage, $v_{z 1 l}$, 


$$
v_{z 1 l}=\frac{\varepsilon}{r_{0} l_{w y}} y_{w 1}
$$

arising from the thickness of the contact patch, includes the contact angle parameter, $\varepsilon$ [30]. The contact patch dimension product, defined as $a b$,

$$
a b=\left[\frac{1.5\left(1-v^{2}\right) N r_{0}}{E}\right]^{2 / 3}
$$

is a function of the average normal force of the vehicle per wheel, $N$, Poisson's Ratio of steel, $v$, and the nominal wheel radius, $r_{0}$. To perform the conversion from creepages to creep forces, creep force coefficients $f_{11}, f_{22}$ and $f_{23}$,

$$
\begin{aligned}
& f_{11}=E C_{11} a b, \\
& f_{22}=E C_{22} a b, \\
& f_{23}=E C_{23} a b,
\end{aligned}
$$

which depend respectively on the Kalker coefficients $c_{11}, c_{22}$ and $c_{23}$ [36] are determined. The longitudinal and lateral creep forces,

$$
\begin{gathered}
F_{x 1 l}=f_{11} v_{x 1 l}, \\
F_{y 1 l}=f_{22} v_{y 1 l}+f_{23} v_{z 1 l},
\end{gathered}
$$

respectively, are then used to calculate $T_{\gamma}$,

$$
T_{\gamma 1 l}=F_{x 1 l} v_{x 1 l}+F_{y 1 l} v_{y 1 l}
$$

\section{Appendix C. Optimised Suspension Parameter Values}

Figures C1 and C2 detail the optimised suspension parameter values which should be read in conjunction to the analysis in Section 4. 


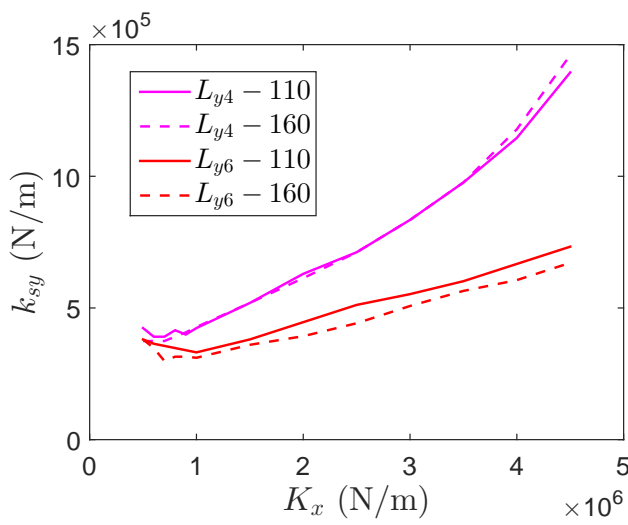

(a) Optimised lateral stiffness parameters.

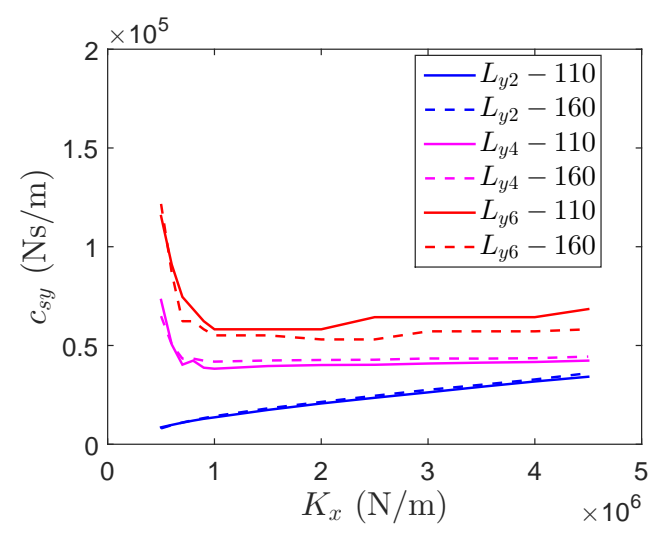

(c) Optimised lateral damping parameters.

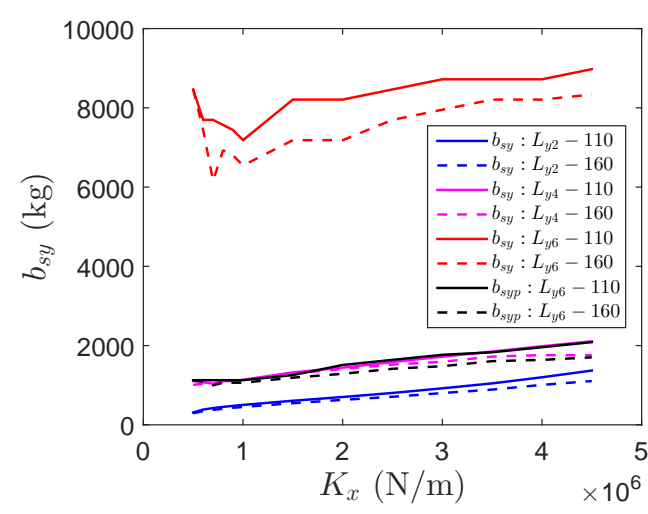

(e) Optimised lateral inertance parameters.

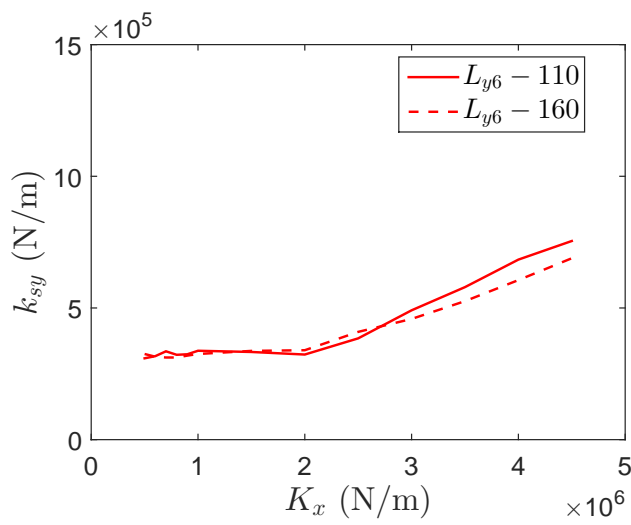

(b) Optimised lateral stiffness parameters when longitudinal Hall-Bush optimisation is also conducted.

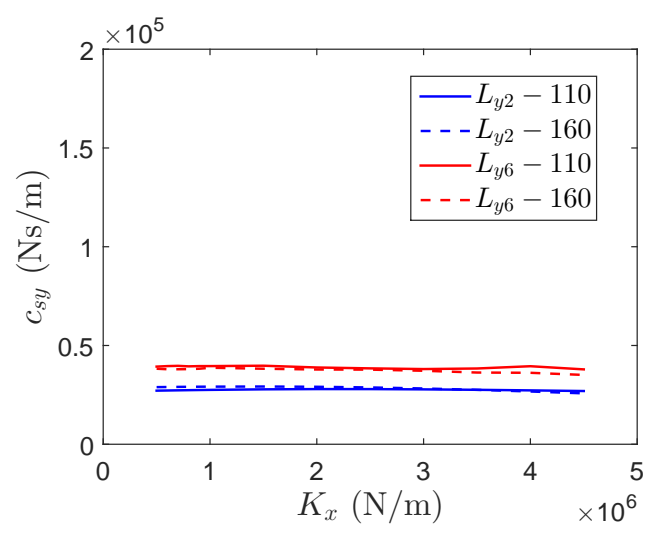

(d) Optimised lateral damping parameters when longitudinal Hall-Bush optimisation is also conducted.

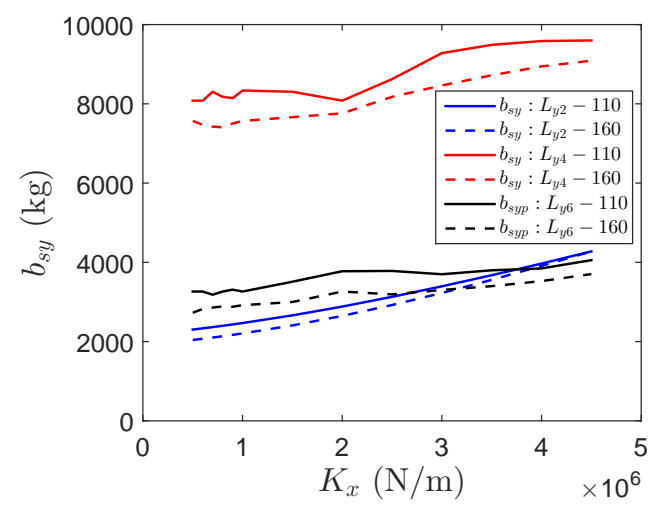

(f) Optimised lateral inertance parameters when longitudinal Hall-Bush optimisation is also conducted.

Figure C1. How optimised parameters of lateral suspension components vary with yaw stiffness, for varying suspension layouts, with and without a Hall-Bush structure in the longitudinal suspension, and for inputs of both Track110 and Track160. Note that when the default longitudinal suspension, $L_{x 1}$, is used (see Figure 3 ), $c_{s x}$ is fixed at $4 \times 10^{3} \mathrm{Nsm}^{-1}$. 


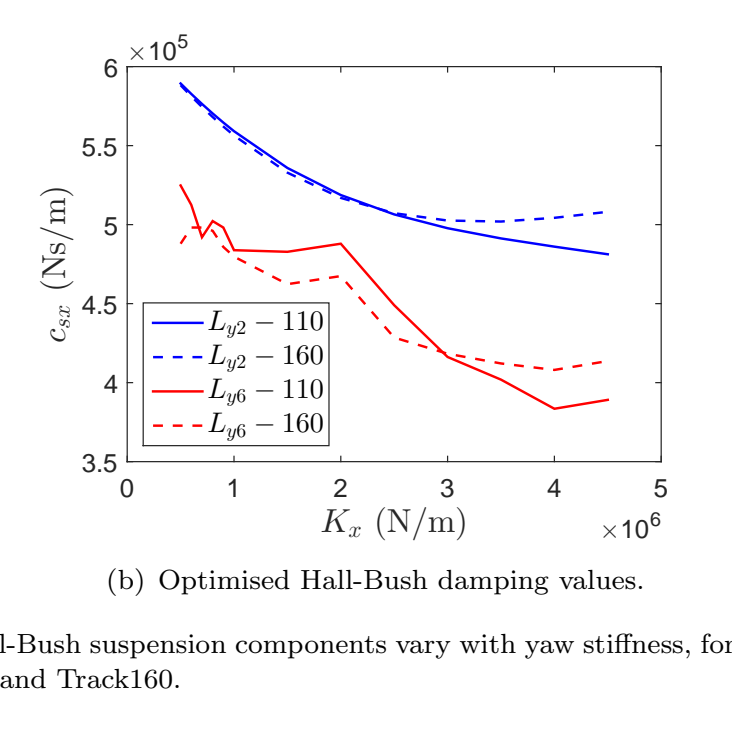

(b) Optimised Hall-Bush damping values.

\begin{abstract}
components vary with yaw stiffness, for
\end{abstract}

(1)

Figure C2. How optimised parameters longitudinal Hall-Bush suspension components vary with yaw stiffness, for

(a) Optimised Hall-Bush stiffness values.

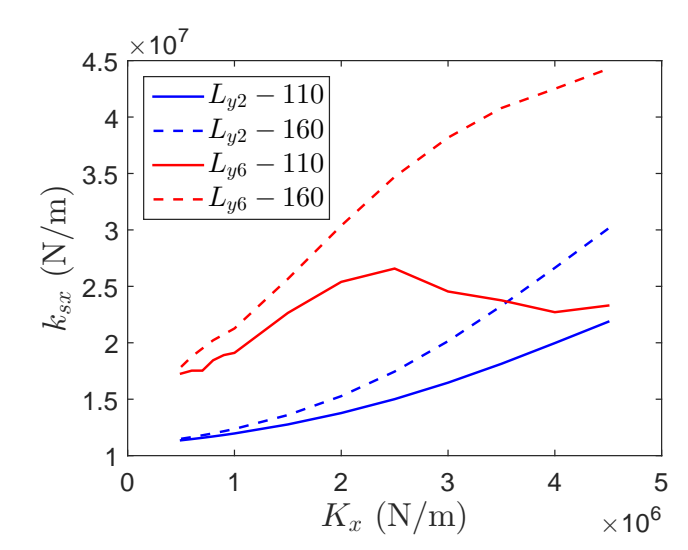

varying suspension layouts for inputs of both Track110 and Track160.
ב

(n)

.

.

.

.

. . 